\title{
ALTERNATIVE TECHNIQUE TO REMOVE LATERAL PERIODONTAL CYSTLIKE LESION: THE TUNNELLING APPROACH
}

Ngeow WC, P. Shanmuhasuntharam. Alternative technique to remove lateral periodontal cystlike lesion; the tunnelling approach, Annals Dent Univ Malaya 1997; 4: 23-25

\begin{abstract}
Surgery done around gingival margin may eventually result in loss of attachment and recession of the gingiva. Root hypersensitivity is another possible complication when coupled with overzealous tooth brushing by the patients. This paper presents an alternative method to remove a lesion located at the lateral cervical third of a root. Its advantage is that the gingival margin is kept intact.
\end{abstract}

Key words: gingival recession, loss of attachment, semilunar incision, tunnel

\section{INTRODUCTION}

Lateral periodontal cystlike lesions are lesions which develop at the lateral periodontium. They are relatively uncommon but widely recognised pathology of the dentoalveolar structure. The most common lateral periodontal cystlike lesion is the lateral periodontal cyst $(1,2,3)$. Other diagnoses include lateral radicular cyst and odontogenic keratocyst $(4,5)$. Lateral periodontal cystlike lesions are mostly discovered during routine radiographic examination as pain or other clinical symptom is seldom reported $(1,2,3,4)$.

Most often when the lateral periodontal cystlike lesion originates from a non-vital tooth, root canal therapy is the treatment of choice. Usually these lesions will eventually subside. However, root canal treatment is of no use when dealing with lateral periodontal cyst of developmental origin. In such a situation, the clinician may opt to observe the lesion with periodic reviews if they are found by chance and do not present with signs and symptoms. Some of these lesions may eventually be biopsied.

Surgical removal of lateral periodontal cystlike lesions is usually done by raising a trapezoidal flap and enucleating the lesion. This technique has its drawback as it may result in gingiva margin recession which may measure between 0.5 to 1 $\mathrm{mm}$ even though it is done properly (6). Cervical osseous defect will happen when the bone between the alveolar margin and the lesion has to be removed. (See [A] in Figure1) Some patients may even complain of root hypersensitivity as a sequalae of the gingival margin recession, especially if the patients practice overzealous tooth brushing (7).

In order to avoid these adverse effects, the authors have adopted the use of a tunnelling approach to remove such lesion. The procedure is detailed below.

\section{TECHNIQUE}

A semilunar incision is made using a no. 15 surgical blade (Figure 2). Care must be taken to ensure that the margin of the flap would not be resting on a defective
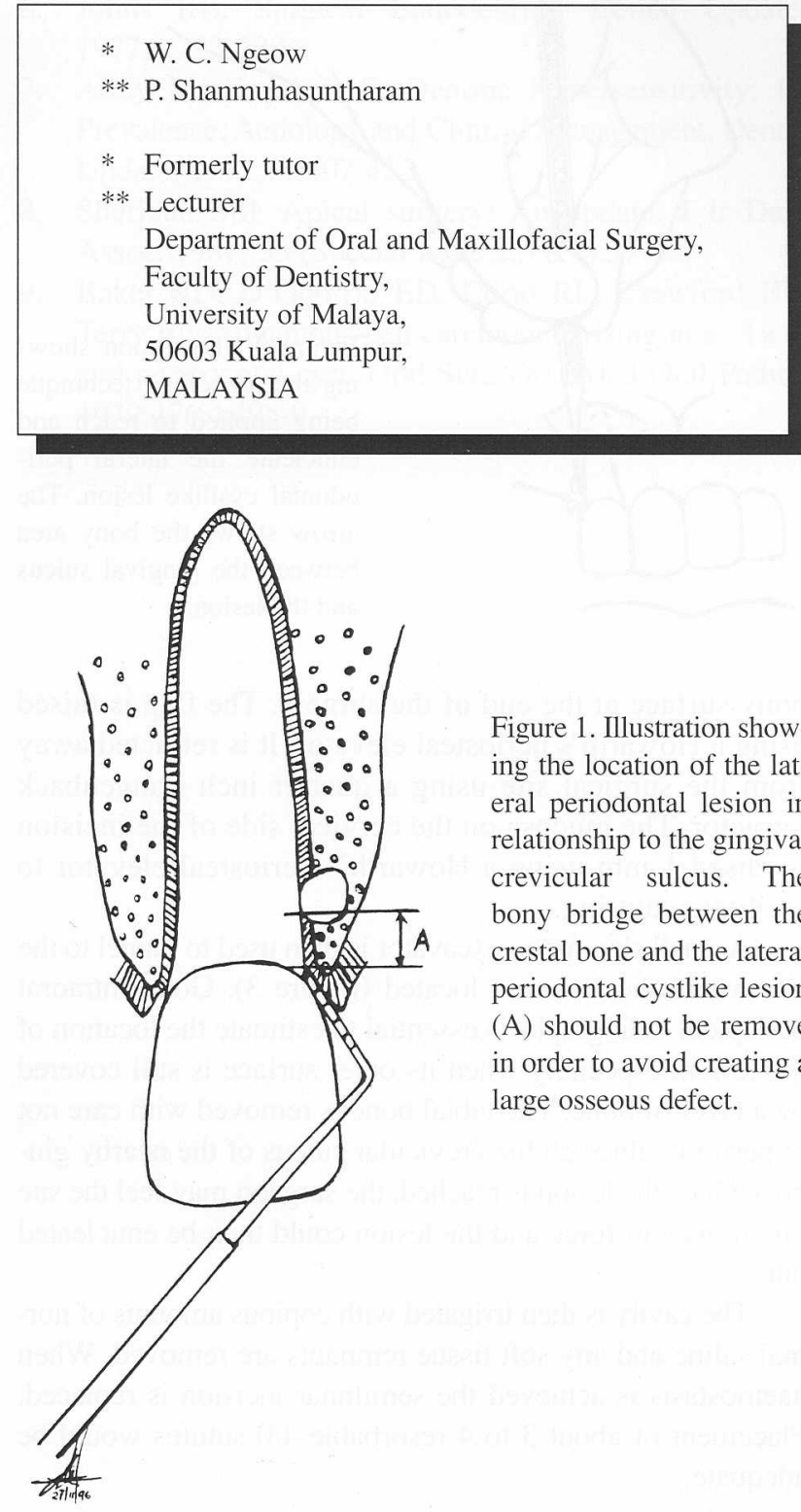

Figure 1. Illustration showing the location of the lateral periodontal lesion in relationship to the gingival crevicular sulcus. The bony bridge between the crestal bone and the lateral periodontal cystlike lesion (A) should not be remove in order to avoid creating a large osseous defect.

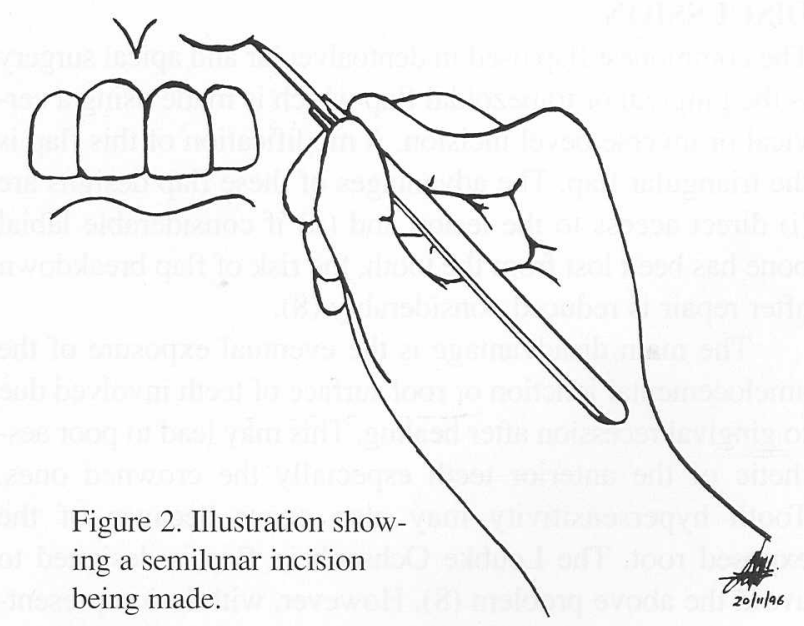




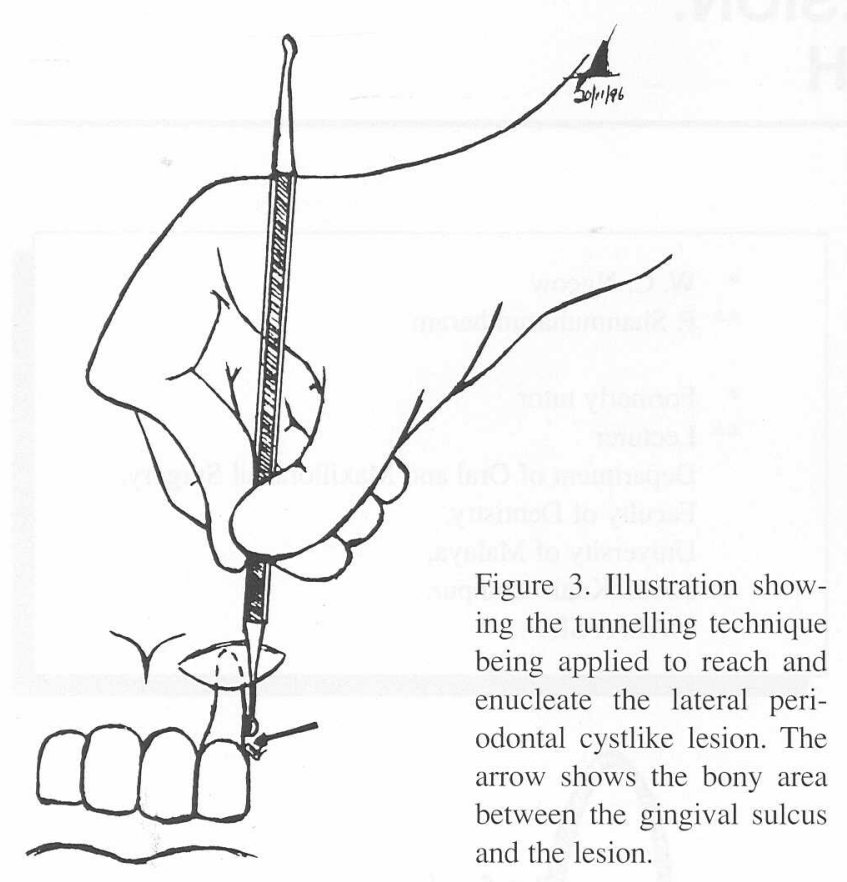

bony surface at the end of the surgery. The flap is raised using a Howarth's periosteal elevator. It is retracted away from the surgical site using a quarter inch Langenback retractor. The mucosa on the cervical side of the incision is raised $1 \mathrm{~mm}$ using a Howarth's periosteal elevator to facilitate suturing.

A small size spoon excavator is then used to tunnel to the site where the lesion is located (Figure 3). Good intraoral periapical radiographs is essential to estimate the location of the lesion, especially when its outer surface is still covered by a layer of bone. The labial bone is removed with care not to perforate through the crevicular sulcus of the nearby gingiva. Once the lesion is reached, the surgeon may feel the site giving way to force and the lesion could then be enucleated out.

The cavity is then irrigated with copious amounts of normal saline and any soft tissue remnants are removed. When haemostasis is achieved the semilunar incision is replaced. Placement of about 3 to 4 resorbable $4 / 0$ sutures would be adequate.

\section{DISCUSSION}

The commonest flap used in dentoalveolar and apical surgery is the gingival or trapezoidal flap which is made using a cervical or inverse bevel incision. A modification of this flap is the triangular flap. The advantages of these flap designs are (i) direct access to the lesion and (ii) if considerable labial bone has been lost from the tooth, the risk of flap breakdown after repair is reduced considerably (8).

The main disadvantage is the eventual exposure of the amelocemental junction or root surface of teeth involved due to gingival recession after healing. This may lead to poor aesthetic of the anterior teeth especially the crowned ones. Tooth hypersensitivity may also occur because of the exposed root. The Leubke Ochsenbein flap is designed to avoid the above problem (8). However, with lesion present- ing on the lateral aspect of the cervical third of a root, the margin of the Leubke Ochsenbein flap may rest on the surgical defect. For this reason, a mucoperiosteal flap made via semilunar incision was preferred. The semilunar incision could be made at the middle or apical third of the root depending on the location of the lesion. The incision must be well clear of the lesion. The lesion is reached by tunnelling underneath the healthy mucosa.

Even when designing this flap, the general principles of flap design should be adhered to. The edges of the flap should rest over sound bone to prevent breakdown and the reflection should be as atraumatic as possible to avoid damaging the flap margins (7).

The colour and texture of the attached gingiva around the tooth should be compared with adjacent tissue. Dark or swollen gingiva may indicate the presence of the lateral periodontal lesion. When a lateral periodontal lesion cannot be seen clinically, it is of course difficult to determine the margin of the incision. The use of a good intraoral periapical radiograph taken using the parallel technique is of utmost importance as it gives an indication of the size and location of the lesion without distortion of image. The determination of the location of the lesion will have a direct influence on the type of mucoperiosteal flap used for access. For example if the lesion is located at the middle third or apical third of the root, the Leubke Ochsenbein flap could be utilised. On the other hand if it is located at the cervical third of the root, the authors prefer a mucoperiosteal flap made via a semilunar incision.

By using the technique described above, the authors avoided creating a communication iatrogenically between the lateral periodontal lesion and the gingival crevicular sulcus (Site A in Figure 1) by tunnelling toward the lesion from the apical end instead of the commonly used cervical approach. In this instance, by not making a trapezoidal flap, the gingival crevicular sulcus was left intact.

The lesion was enucleated after removing a small piece of bone overlying the lesion but no bone was removed at the cervical aspect of the root. There may be a fenestration in the bone in the lesion site and no bone need to be removed at all. Care is taken when removing the lesion so that the periodontal apparatus of the root surface is not damaged as any damage may eventually result in root resorption.

This technique is not without its disadvantages as there is always a potential of flap breakdown if the margin of the surgical flap is left overlying a defective cavity. Moreover, the enucleation of the lesion is done blindly via a tunnel, thus the removal of lesion suspected of neoplastic nature (9) or of high recurrence rate (5) is not advisable by this technique. All biopsy specimens obtained should be sent for histopathological examination. However, should this technique become successful, no iatrogenic gingival margin recession will occur thus avoiding any periodontal and root hypersensitivity complication.

\section{SUMMARY}

An alternative approach to remove lateral periodontal cystlike lesion using the tunnelling technique is presented. This 
technique avoided the creation of gingival margin recession at the surgical site, thus reducing the possibility of post-operative root hypersensitivity of the tooth concerned.

\section{REFERENCES}

1. Fantasia JE. Lateral periodontal cyst. An analysis of forty-six cases. Oral Surg Oral Med Oral Pathol. 1979;48(3):237-43.

2. Altini M, Shear M. The lateral periodontal cyst: an update. J Oral Pathol Med. 1992;21(6):245-50.

3. Rasmusson LG, Magnusson BC, Borrman H. The lateral periodontal cyst. A histological and radiographical study of 32 cases. Br J Oral Maxillofac Surg. 1991;29(1):54-7.

4. Waldron CA. Odontogenic cyst and tumors. In Neville BW, Damm DD, Allen CM, Bouquot JE (eds). Oral and Maxillofacial Pathology. Philadelphia: W. B. Saunders Co., 1995:493-540.

5. Neville BW, Mishkin DJ, Traynham RT. The laterally positioned odontogenic keratocyst. A case report. J Periodontal. 1984;55(2):98-102.

6. Johns RB. Surgical Endodontics. Dental Update, 1977;4:223-229

7. Addy M, Urquhart E. Dentine Hypersensitivity: Its Prevalence, Aetiology and Clinical Management. Dental Update, 1992;19:407-412

8. Sheridan SM. Apical surgery: An update. J Ir Dent Assoc. 1987; 33 (Special Issue 2,3 \&4):37-40.

9. Baker RD, D’Onofrio ED, Corio RL, Crawford BE, Terry BC. Squamous-cell carcinoma arising in a 1 a t eral periodontal cyst. Oral Surg Oral Med Oral Pathol. 1979;47(6):495-9. 